\title{
The response of short-duration pigeonpea lines to variation in temperature under field conditions in Kenya
}

\author{
S.N. Silim ${ }^{a, *}$, P.A. Omanga ${ }^{b}$ \\ anternational Crops Research Institute for the Semi-Arid Tropics (ICRISAT), P.O. Box 39063, Nairobi, Kenya \\ ${ }^{\mathrm{b}}$ National Dryland Farming Research Centre, P.O. Box 340, Machakos, Kenya \\ Received 15 June 1999; received in revised form 1 May 2001; accepted 17 May 2001
}

\begin{abstract}
Field studies with pigeonpea (Cajanus cajan (L.) Millsp.) were conducted at four locations in Kenya varying in altitude and where temperature decreased with increase in altitude. Warm temperatures (most inductive temperatures, mean $23.5^{\circ} \mathrm{C}$ ) hastened the times from sowing to flowering $(f)$ and maturity $(m)$, and between flowering and maturity $(\mathrm{fm})$. Cool temperatures $\left(17.8^{\circ} \mathrm{C}\right)$ delayed $f, m$, and $f m$ but the delay was most pronounced for $f m$. In the least inductive cool environment, variation in $f$, $m$ and $f m$ was greatest among 63 lines developed in India. Compared to the most inductive temperature, the delay in cool environment was 2.2 for $f, 3.1$ for $m$, and 5.5 for $f m$, which indicates that $f m$ is the most sensitive phase to low (sub-optimal) temperatures.

Equations that describe the rates of development $(1 / \mathrm{f}, 1 / \mathrm{m}$, and $1 / \mathrm{fm})$ were used to determine progress to different stages of development. Results revealed that optimum temperature for fastest time to flowering varied from 23.1 to $26.1^{\circ} \mathrm{C}$. The $1 / f$ at mean temperature of $26.8^{\circ} \mathrm{C}$ was slower, indicating that the mean temperature experienced was supra-optimal. Since the mean temperature of $26.8^{\circ} \mathrm{C}$ was not very different from the range considered optimal, further analysis revealed that this was mainly due to the high night temperatures. The $1 / \mathrm{fm}$ was strong and positive in the range of temperature tested indicating that warm temperatures shortened the duration between flowering and maturity. The optimum temperature range for this effect varied from 24 to $32^{\circ} \mathrm{C}$. Cool temperatures at Kabete retarded plant growth while warm temperatures enhanced it. (C) 2001 Elsevier Science B.V. All rights reserved.
\end{abstract}

Keywords: Pigeonpea; Temperature; Phenology

\section{Introduction}

Pigeonpea (Cajanus cajan (L.) Millsp.) is a major grain legume crop in the tropics and subtropics (Nene and Sheila, 1990). In these areas, daylength varies from 11 to $14 \mathrm{~h}$ and large differences in temperature are experienced, largely due to variations in altitude

\footnotetext{
* Corresponding author. Tel.: +254-2-524-555; fax: +254-2-524-001.

E-mail address: s.silim@cgiar.org (S.N. Silim).
}

and latitude. The crop is extremely sensitive to photoperiod and temperature, with plant height, vegetative biomass, phenology, and grain yield being the traits most affected (Byth et al., 1981; Whiteman et al., 1985). This sensitivity is a major constraint to development of stable and predictable management practices, cropping systems, and lines (Whiteman et al., 1985). A delay in maturity, e.g., may interfere with proper timing of the succeeding crop. A delay in maturity may also reduce yield in areas where rainfall duration is short and the crop must depend on residual 
soil moisture. In areas with bimodal rainfall, such as Kenya, acceleration of development may result in reproductive growth occurring between the two rainfall periods and the crop would thus suffer from drought stress at the time when it is most sensitive.

Concerted research efforts, particularly by ICRISAT, have resulted in development of extra-short- and shortduration lines that escape terminal drought and are relatively less sensitive to photoperiod than traditional types with longer growth cycles (Singh et al., 1990). This has increased the flexibility of pigeonpea cultivation and facilitated its use in different cropping systems (Nene, 1991). These new lines remain sensitive to temperature, however and their cycles are too long for use in cool areas.

The first step towards maximising yield is to ensure that the phenology of the crop matches the resources of the production environment (Richards, 1989). The most common approach is pragmatic and involves growing large numbers of germplasm accessions and breeding lines in multiple environments to test their phenological adaptation. An alternative approach is to measure environmental effects on phenology, the most important being time taken to a particular event. Summerfield et al. (1991) described a series of models useful in predicting phenological events. Flowering is characterised not as time to flower $(f)$ but as rate of progress towards flowering (i.e., $1 / f$, the reciprocal of the time taken) and it is assumed to vary with photoperiod and temperature. The temperature range in which plant growth and development occur is characterised by a base temperature $\left(T_{\mathrm{b}}\right)$ below which the rate of development is zero, an optimum temperature $\left(T_{\mathrm{o}}\right)$ at which the rate of development is most rapid, and a warmer ceiling limit $\left(T_{\text {ce }}\right)$ beyond which development ceases (Summerfield et al., 1991). The extrashort- and short-duration pigeonpea lines are sensitive to temperature, but relatively less sensitive to photoperiod. In pigeonpea, optimum temperatures for flowering vary with maturity groups (Omanga et al., 1995, 1996). The temperature range at which time taken to flower is most rapid is $24-27^{\circ} \mathrm{C}$ (warm temperatures) for extra-short and short-duration, $20-24^{\circ} \mathrm{C}$ (cool temperatures) for medium-duration and $18-20^{\circ} \mathrm{C}$ (cooler temperatures) for long-duration lines (Turnbull et al., 1981; McPherson et al., 1985; Omanga et al., 1995, 1996). However, little information is available on the effect of temperature on the duration and rate of development in the period between flowering and maturity.

One of the objectives for developing extrashort- and short-duration pigeonpeas is to fit them into non-traditional cropping systems. These include growing pigeonpea in rotation with wheat during summer in the subtropics, or rice. Pigeonpeas grown in the subtropics experience temperatures cooler than those in the traditional areas during the later part of their growth, and those grown in high altitude areas experience cool temperatures during whole of their life cycle. Unfortunately, selection for earliness in a warm climate and relative insensitivity to photoperiod has resulted in development of lines adapted to warm temperatures (Omanga et al., 1995). What is now urgently needed is either to develop or search for lines in the extra-short- or short-duration groups that are not delayed by cool temperatures so that growing of pigeonpea can be extended to cooler environments.

This study investigated genetic variability in response to temperature (particular attention was given to low temperatures) for pre- and post-flowering durations of extra-short- and short-duration pigeonpeas, and to assess the value of the Kenyan transect for screening pigeonpea lines. Particular attention was given to low temperatures.

\section{Materials and methods}

\subsection{Genetic materials}

The experiment comprised of 64 extra-short- and short-duration pigeonpea lines; of these, 63 had been developed at ICRISAT at Patancheru in India (Andhra Pradesh) at $17^{\circ} \mathrm{N}$ and $500 \mathrm{~m}$ altitude. KAT 60/8 developed at the National Dryland Farming Research Centre (NDFRC-Katumani, $1^{\circ} 35^{\prime} \mathrm{S} ; 1560 \mathrm{~m}$ altitude) in Kenya was used as a control. These materials included extra-short-duration $(<105$ days to mature at ICRISAT in India) and short-duration lines ( $>105$ days to mature at ICRISAT in India) with either determinate or indeterminate growth habits.

\subsection{Environments}

The field experiments were conducted in Kenya at four locations varying in altitude from 50 to about 
Table 1

Latitude, altitude, long term mean temperatures, and seasonal rainfall for the study sites in Kenya

\begin{tabular}{|c|c|c|c|c|c|c|c|c|}
\hline \multirow[t]{2}{*}{ Location } & \multirow[t]{2}{*}{ Latitude (S) } & \multirow[t]{2}{*}{ Altitude (m) } & \multirow[t]{2}{*}{ Soil type } & \multirow[t]{2}{*}{ Season $^{\mathrm{a}}$} & \multicolumn{3}{|c|}{ Temperatures $\left({ }^{\circ} \mathrm{C}\right)$} & \multirow[t]{2}{*}{ Rainfall (mm) } \\
\hline & & & & & Maximum & Minimum & Mean & \\
\hline \multirow[t]{2}{*}{ Mtwapa } & \multirow[t]{2}{*}{$4^{\circ} 25^{\prime}$} & \multirow[t]{2}{*}{50} & Deep sandy & SR & 31.4 & 23.2 & 27.3 & 370 \\
\hline & & & Clay loam & LR & 28.9 & 21.5 & 25.2 & 679 \\
\hline \multirow[t]{2}{*}{ Kiboko } & \multirow[t]{2}{*}{$2^{\circ} 20^{\prime}$} & \multirow[t]{2}{*}{900} & Sandy clay & SR & 29.4 & 17.7 & 23.5 & $464^{\mathrm{b}}$ \\
\hline & & & Loam, calcareous & LR & 27.8 & 15.5 & 21.6 & $140^{\mathrm{b}}$ \\
\hline \multirow[t]{2}{*}{ Katumani } & \multirow[t]{2}{*}{$1^{\circ} 35^{\prime}$} & \multirow[t]{2}{*}{1560} & Very deep, sandy & SR & 25.6 & 14.4 & 20.0 & 467 \\
\hline & & & Loam to clay & LR & 23.6 & 12.9 & 18.2 & 244 \\
\hline \multirow[t]{2}{*}{ Kabete } & \multirow[t]{2}{*}{$1^{\circ} 15^{\prime}$} & \multirow{2}{*}{1825} & Extremely deep & SR & 24.6 & 12.9 & 18.7 & 478 \\
\hline & & & Friable clay & LR & 22.1 & 12.2 & 17.1 & 518 \\
\hline
\end{tabular}

${ }^{\text {a }}$ SR: short rains (October-February); LR: long rains (April-September).

${ }^{\mathrm{b}}$ Received supplemental irrigation.

$1825 \mathrm{~m}$ (Table 1). The lower elevation locations (Mtwapa, Kiboko and Katumani) are traditional areas of production, whereas the high elevation site (Kabete) is not. In order to take advantage of seasonal variation in temperature, the trials were sown during the onset of short (October-November) and long (March-April) rains at Kiboko and Kabete. At Mtwapa on the coast, the cropping season is March-August, hence sowing was during the long rains.

\subsection{Experimental design and management}

The experiments were conducted using an $8 \times 8$ square lattice design with three replications. All 64 pigeonpea lines were bred lines. Sixty three lines were bred at ICRISAT, Patancheru, India and one at the National Dryland Farming Research Centre, Kenya. The lines used in the study comprised of extra-short-duration (80-90 days to reach maturity at Patancheru, India) and short-duration (90-110 days to reach maturity at Patancheru) lines in both determinate and indeterminate growth-habit backgrounds. At all locations, land was ploughed and harrowed into a fine tilth and seeds were sown by hand. Each line was sown in plots consisting of three rows, $5 \mathrm{~m}$ long. Plant spacings were $0.4 \mathrm{~m}$ between rows and $0.1 \mathrm{~m}$ within rows. Three to four seeds were sown in each hill. Fourteen days after emergence, seedlings were thinned to one per hill. Weeds were controlled by hand weeding and plants effectively protected against insect pests during flowering and post-flowering phases by insecticidal sprays. Fertilisers were not applied, as previous studies had indicated that the crop does not respond to fertiliser application at these locations, and seeds were not inoculated with rhizobia. No mineral deficiency symptoms were noticed during crop growth. At Kiboko, the driest location, the trials were irrigated to avoid water deficit. In other locations, the crop did not experience water deficit.

\subsection{Data collection}

Phenological data were recorded on successive events, i.e., days from sowing to when $50 \%$ of plants in a plot had at least one open flower $(f$, referred to as flowering), and time from sowing to when $75 \%$ of pods in a plot turned brown ( $m$, referred to as maturity). The post-flowering duration $(f m)$, i.e., time from flowering to maturity was obtained from the difference between number of days to maturity and flowering. Plant height was recorded at flowering on five plants in each plot. Daily maximum and minimum temperatures were obtained from meteorological stations located within $400 \mathrm{~m}$ of the experiments. The mean pre-flowering maximum $\left(T_{\max }\right)$ and minimum $\left(T_{\min }\right)$ temperatures for each line in each environment were calculated by dividing the sum of daily values from sowing until $50 \%$ of the plants in a plot had at least one open flower (flowering) by the number of days taken. Mean pre-flowering temperatures were then calculated as $\frac{1}{2}\left(T_{\max }+T_{\min }\right)$. Temperatures between 
flowering and maturity $(75 \%$ of pods in a plot turned brown) were processed in the same way.

\subsection{Data analyses}

The responses to temperature of times from sowing to flowering $(f)$, flowering to maturity $(f m)$, and sowing to maturity $(m)$, and plant height $(h)$ were derived from means for each line-environment. Rates of progress within these phenostages were calculated as the reciprocals of these durations. Individual rates of development for pre- and post-flowering phases were then examined in terms of mean temperatures using the protocol developed by Summerfield et al. (1991). Because the photothermal environments to which the plants were exposed included both sub- and supraoptimal temperatures, additional procedures described by Omanga et al. (1995) were also adopted. In these procedures, data for each line were first fitted to Eq. (1):

$\frac{1}{f}=a_{1}+b_{1}\left(T-T_{\mathrm{o}}\right)+b_{2}\left|T-T_{\mathrm{o}}\right|$

where $T_{\mathrm{o}}$ is the apparent optimal temperature to be estimated, $a_{1}$ the apparent maximal rate of progress to flowering when $T=T_{0}$, the parameter constants $b_{1}$ and $b_{2}$ combine to determine the flowering response to the entire temperature range from $T_{\mathrm{b}}$ (base) to $T_{\mathrm{ce}}$ (ceiling), and the symbol $\|$ is the absolute value of the difference between $T$ and $T_{\mathrm{o}}$. When $T>T_{\mathrm{o}}$, then $\left|T-T_{\mathrm{o}}\right|=T=T_{\mathrm{o}}$, whereas when $T<T_{\mathrm{o}}$, then $\left|T-T_{\mathrm{o}}\right|=T_{\mathrm{o}}-T$. Eq. (1) assumes that $1 / f$ is modulated solely by temperature, that some thermal environments had significantly transgressed $T_{\mathrm{o}}$ (plants were exposed to sub- and supra-optimal temperatures), and that temperature responsiveness below and above $T_{\mathrm{o}}$ may differ.

If significant transgression of optimum temperature is detected, then Eq. (1) may be rearranged to describe sub- (Eq. (2)) and supra-optimal (Eq. (3)) temperature responses as shown below.

When $T<T_{\mathrm{o}}$, then

$\frac{1}{f}=a_{1}+\left(b_{2}-b_{1}\right) T_{\mathrm{o}}+\left(b_{1}-b_{2}\right) T$

and $T>T_{\mathrm{o}}$, then

$\frac{1}{f}=a_{1}-\left(b_{2}+b_{1}\right) T_{\mathrm{o}}+\left(b_{1}+b_{2}\right) T$
By substituting the values of $a_{1}, b_{1}, b_{2}$ and $T_{\mathrm{o}}$ from Eq. (1) into Eqs. (2) and (3), the values of the genotypic constants $a$ and $b$ in the thermal model (Summerfield et al., 1991) can be obtained. For example, when $T<T_{\mathrm{o}}$,

$\frac{1}{f}=a+b T$

and when $T>T_{\mathrm{o}}$,

$\frac{1}{f}=a^{\prime \prime}-b^{\prime \prime} T$

where $a$ and $b$ are line-specific constants describing sub-optimal temperature relations while $a^{\prime \prime}$ and $b^{\prime \prime}$ describe supra-optimal temperature relations. $b^{\prime \prime}$ has a negative sign reflecting the fact that increase in temperature above $T_{\mathrm{o}}$ decreases $1 / f$ with no progress at the ceiling temperature $\left(T_{\mathrm{ce}}=-a^{\prime \prime} / b^{\prime \prime}\right)$ and above. Similarly, the relationships of $1 / \mathrm{fm}$ with temperature and $1 / m$ with temperature were also examined.

\section{Results}

\subsection{Weather}

Mean temperatures experienced in each of the 11 environments (Table 2) clearly indicated that the plants were exposed to different temperatures during pre- and post-flowering development phases. Postflowering temperatures were cooler than pre-flowering ones during the long rains (April-sown crop) and warmer during the short rains (November-sown crop). Temperatures were cooler at Kabete (high altitude), but warmer at Mtwapa and Kiboko, the low-altitude locations. At all locations, April-sown crops experienced decreasing temperatures from April to JuneJuly. In contrast, temperatures were warmer for the November-sown crop with only slight increases from November to January.

\subsection{Effect of temperature}

There were large differences across the environments for mean $f, f m, m, h$ (Table 3). Regression analyses revealed that $f, f m$, and $m$ were highly and positively interrelated $(P<0.01)$. However, the correlation coefficients between these traits and mean 
Table 2

Average pre- and post-flowering maximum, minimum and mean temperatures experienced by pigeonpea lines in the 11 environments in Kenya

\begin{tabular}{|c|c|c|c|c|c|c|}
\hline \multirow[t]{3}{*}{ Environments ${ }^{\mathrm{a}}$} & \multicolumn{6}{|c|}{ Temperatures $\left({ }^{\circ} \mathrm{C}\right)$} \\
\hline & \multicolumn{3}{|c|}{ Pre-flowering } & \multicolumn{3}{|c|}{ Post-flowering } \\
\hline & Maximum & Minimum & Mean & Maximum & Minimum & Mean \\
\hline \multicolumn{7}{|l|}{ Mtwapa } \\
\hline LR92 & 29.8 & 23.7 & 26.8 & 27.2 & 21.3 & 24.2 \\
\hline \multicolumn{7}{|l|}{ Kiboko } \\
\hline LR92 & 31.1 & 17.5 & 24.3 & 28.0 & 14.0 & 21.0 \\
\hline SR92 & 29.5 & 18.2 & 23.8 & 29.3 & 16.9 & 23.1 \\
\hline SR93 & 31.5 & 18.5 & 25.0 & 34.5 & 16.5 & 25.5 \\
\hline LR94 & 28.7 & 17.4 & 23.0 & 29.3 & 13.9 & 21.6 \\
\hline SR95 & 29.0 & 18.0 & 23.5 & 32.6 & 16.7 & 24.6 \\
\hline \multicolumn{7}{|l|}{ Katumani } \\
\hline SR92 & 23.7 & 14.6 & 19.1 & 25.6 & 13.9 & 19.8 \\
\hline SR93 & 25.4 & 14.2 & 19.8 & 27.6 & 13.7 & 20.6 \\
\hline \multicolumn{7}{|l|}{ Kabete } \\
\hline SR92 & 23.8 & 13.3 & 18.5 & 24.4 & 13.6 & 19.0 \\
\hline SR93 & 22.8 & 13.7 & 18.2 & 24.9 & 14.2 & 19.5 \\
\hline LR94 & 21.7 & 12.9 & 17.3 & 22.0 & 11.9 & 16.9 \\
\hline
\end{tabular}

${ }^{\text {a }}$ SR: short rains, LR: long rains; and numerals represent years.

Table 3

Means of various characters for the 64 lines in each of the 11 environments in Kenya

\begin{tabular}{|c|c|c|c|c|}
\hline Environments $^{\mathrm{a}}$ & $\begin{array}{l}\text { Days to } 50 \% \\
\text { flowering }(f)\end{array}$ & $\begin{array}{l}\text { Days to } 75 \% \\
\text { maturity }(m)\end{array}$ & $\begin{array}{l}\text { Days from flowering } \\
\text { to maturity }(\mathrm{fm})\end{array}$ & $\begin{array}{l}\text { Plant height } \\
(\mathrm{cm})\end{array}$ \\
\hline \multicolumn{5}{|l|}{ Mtwapa } \\
\hline LR93 & $81.1(2.2)^{\mathrm{b}}$ & $121.8(2.5)$ & 41.1(1.9) & $95.5(4.9)$ \\
\hline \multicolumn{5}{|l|}{ Kiboko } \\
\hline LR92 & $61.4(1.9)$ & $104.5(2.6)$ & $42.5(1.7)$ & $70.4(3.4)$ \\
\hline SR92 & $59.5(1.8)$ & $105.2(2.5)$ & $45.5(2.1)$ & $75.2(4.8)$ \\
\hline SR93 & $60.7(1.6)$ & $94.5(2.5)$ & $33.8(2.1)$ & $73.5(3.6)$ \\
\hline LR94 & $63.4(1.3)$ & $109.7(1.7)$ & $46.1(1.5)$ & $63.8(3.6)$ \\
\hline SR95 & $64.4(1.8)$ & $105.3(2.1)$ & $40.9(1.6)$ & $94.3(4.0)$ \\
\hline \multicolumn{5}{|l|}{ Katumani } \\
\hline SR92 & $73.4(2.1)$ & $126.7(2.5)$ & $53.4(2.0)$ & $66.2(4.5)$ \\
\hline SR93 & $85.1(1.7)$ & $135.6(2.5)$ & $50.8(2.4)$ & $51.7(2.9)$ \\
\hline \multicolumn{5}{|l|}{ Kabete } \\
\hline SR92 & $89.4(1.8)$ & $150.8(2.2)$ & $61.6(1.8)$ & $58.2(4.7)$ \\
\hline SR93 & $80.1(1.8)$ & $122.0(2.0)$ & $41.7(1.4)$ & $61.9(3.6)$ \\
\hline LR94 & $102.5(2.2)$ & $175.4(2.0)$ & $72.9(1.8)$ & $48.2(3.7)$ \\
\hline Mean & $74.6(1.6)$ & $122.0(2.3)$ & $48.2(1.6)$ & $69.0(3.4)$ \\
\hline
\end{tabular}

${ }^{\text {a }} \mathrm{SR}$ : short rains, LR: long rains; and numerals represent years.

${ }^{\mathrm{b}}$ S.E. values are given in brackets. 

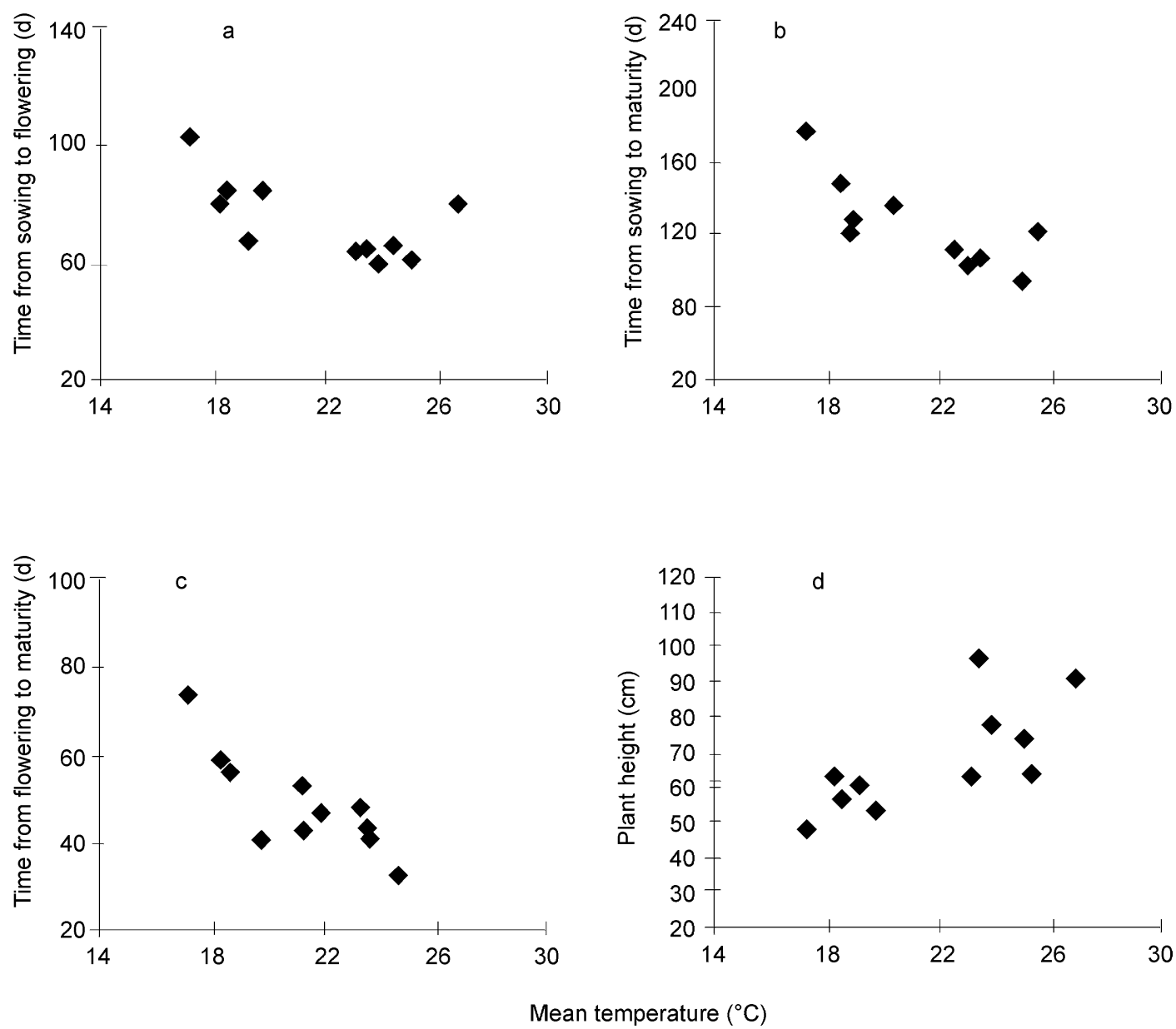

Fig. 1. The influence of mean temperature on times in days from (a) sowing to $50 \%$ flowering $(f)$, (b) sowing to maturity $(m)$, (c) flowering to maturity $(\mathrm{fm})$, and (d) plant height (in $\mathrm{cm}$ ) in extra-short- and short-duration pigeonpea lines grown under field conditions at differing altitudes varying in temperature in Kenya. Means of 11 trials.

pre- and post-flowering temperatures were strong $(P<0.01)$ but negative. Thus, as temperatures decreased from around $25^{\circ} \mathrm{C}$, the durations of these development phases were extended (Fig. 1). At lower temperatures, plant growth was retarded and $h$ for the short-duration lines was negatively $(P<0.01)$ correlated with $f, m$, and $f m$, but strongly and positively associated with mean temperature.

Within each environment, differences among lines were small. In all lines, the duration of $f$ and $f m$ were hastened by the warm temperature (mean $23.5^{\circ} \mathrm{C}$ ) experienced at Kiboko, i.e., the most inductive environment, and delayed most in the cool $\left(17.8^{\circ} \mathrm{C}\right)$ temperatures of Kabete (Table 3). For these extra- short- and short-duration lines, cooler temperatures in the least inductive environments retarded plant growth. Fig. 2 presents examples of the response of three representative lines to temperature variations: ICPL 84023 (extra-short-duration), ICPL 87091 (short-duration) and KAT 60/8 (short-duration bred in cool environment).

Except for KAT 60/8 which was late and flowered in 73 days, matured in 143 days and took 68 days between time to $50 \%$ flowering and maturity in the most inductive environment, the remaining 63 lines were early and there were no remarkable differences in $f$ (55-65 days), $m$ (89-99 days), or $f m$ (30-38 days) between them. Similar behaviour of the 63 lines in the 

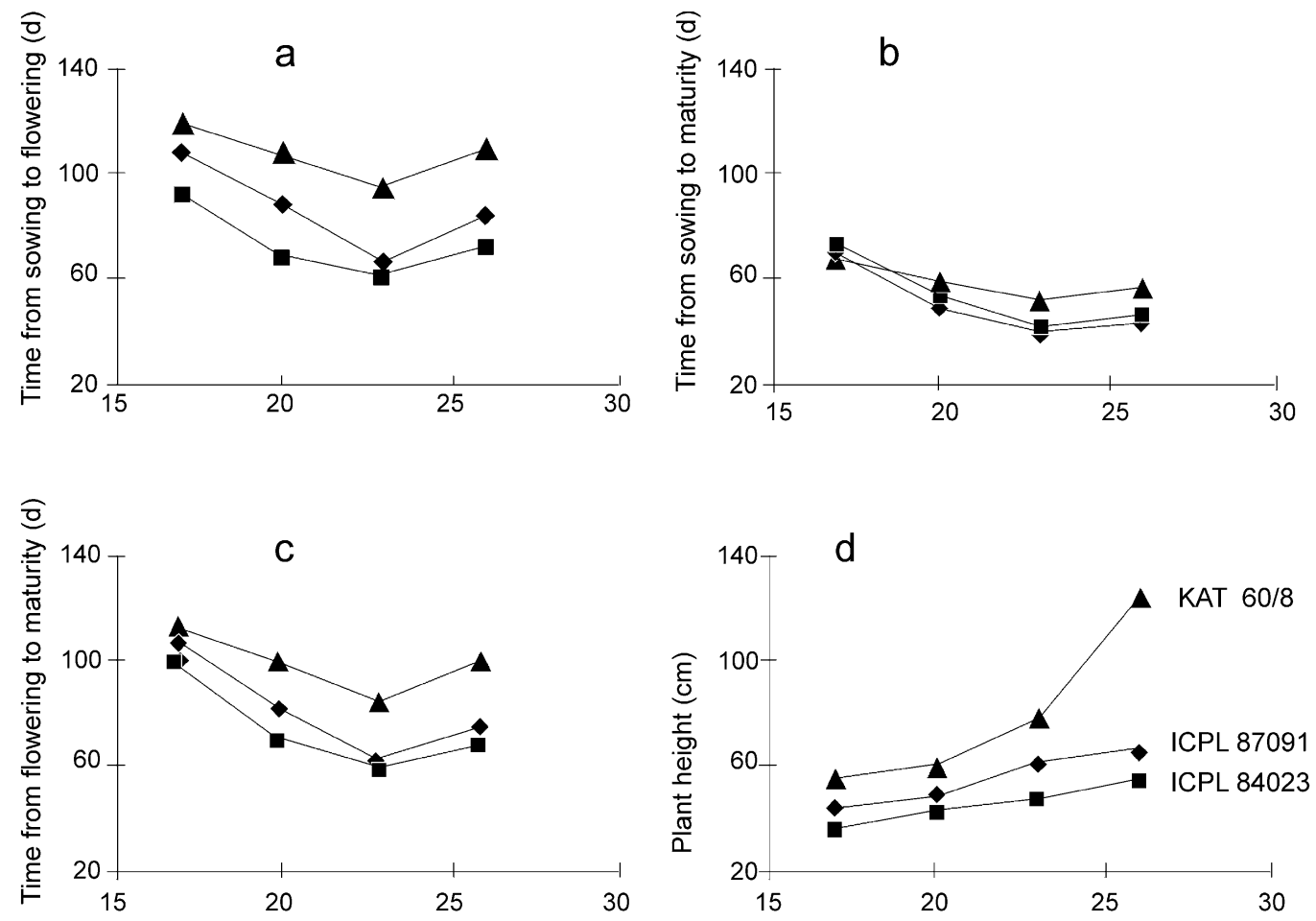

Mean temperature $\left({ }^{\circ} \mathrm{C}\right)$

Fig. 2. The influence of mean temperature on times in days from (a) sowing to $50 \%$ flowering $(f)$, (b) sowing to maturity $(m)$, (c) flowering to maturity $(\mathrm{fm})$, and (d) plant height (in $\mathrm{cm}$ ) for three lines ICPL 84023 (determinate extra-short-duration), ICPL 87091 (determinate shortduration) and KAT 60/8 (indeterminate short-duration) grown under field conditions at differing altitudes varying in temperature in Kenya.

most inductive thermal environment indicates similar inherent earliness among those determinate and nondeterminate lines. Similarly, variation in plant height among lines was small except that the indeterminate lines grew very tall in the warmest environment at Mtwapa.

Under low (sub-optimal) temperatures, phenology was delayed; mean values were 103 days for $f, 176$ days for $m$, and 72 days for $f m$ (see Table 3, Kabete LR94 and Table 4). In addition, variations among the tested lines for $f$ ( $92-112$ days), $m$ (165-182 days), and fm (65-80 days) were very large, indicating that differences among lines are best expressed under low temperatures. Surprisingly, $m$ and $f m$ of KAT $60 / 8$, a relatively late-maturing line, were remarkably stable when compared to other lines. The means under low temperatures for $f, m$ and $f m$ were, respectively, 1.7, 1.9 and 2.1 times greater than those under optimal temperatures, indicating that low temperature delayed phenology with greatest influence on $\mathrm{fm}$ (Table 4).

Remarkable differences were evident among the 64 lines for sensitivity to both coolest and warmest temperatures. Differences among lines for $f$ and $f m$ were more pronounced in the coolest temperature environment (Fig. 3). The variation was particularly strong for $f$. In contrast, $h$ varied more in the warmest than in the coolest temperatures.

Although no line could be classified as insensitive to temperature for $f, m$, and $f m$, some lines were less affected by the extreme temperatures than others. KAT 60/8 developed at NDFRC-Katumani was the least sensitive to both warm and cool temperatures. Among the lines developed by ICRISAT in India, $f$ and $f m$ of ICPL 87105, ICPL 84031, ICPL 91031, and ICPL 91033 were relatively less sensitive to cool and warm temperatures; ICPL 90029, ICPL 87B, and ICPL 
Table 4

Mean values in days of the various characters of extra-short- and short-duration pigeonpea lines grown in cool $\left(17.8^{\circ} \mathrm{C}\right)$, optimal $\left(23.5^{\circ} \mathrm{C}\right)$ and warmest $\left(26.8^{\circ} \mathrm{C}\right)$ in relation to the most inductive $\left(23.5^{\circ} \mathrm{C}\right)$ environments in Kenya and percentage relative change in cool and warmest environments compared to optimum

\begin{tabular}{|c|c|c|c|c|c|c|}
\hline \multirow[t]{2}{*}{ Characters } & \multicolumn{4}{|c|}{ Environments $^{\mathrm{a}}$} & \multicolumn{2}{|c|}{ Relative effect ( $\%$ delay) in } \\
\hline & $\begin{array}{l}\text { Cool } \\
\left(17.8^{\circ} \mathrm{C}\right)\end{array}$ & $\begin{array}{l}\text { Optimal } \\
\left(23.4^{\circ} \mathrm{C}\right)\end{array}$ & $\begin{array}{l}\text { Warm } \\
\left(26.8^{\circ} \mathrm{C}\right)\end{array}$ & Mean $^{\mathrm{b}}$ & $\begin{array}{l}\text { Cool } \\
\text { environment }\end{array}$ & $\begin{array}{l}\text { Warm } \\
\text { environment }\end{array}$ \\
\hline Days to $50 \%$ flower & 103 & 60 & 80 & 74 & 68 & 31 \\
\hline Days to $75 \%$ maturity & 176 & 94 & 121 & 123 & 87 & 28 \\
\hline Post-flowering duration (days) & 72 & 34 & 41 & 48 & 111 & 20 \\
\hline Plant height $(\mathrm{cm})$ & 48 & 74 & 91 & 68 & -35 & 22 \\
\hline
\end{tabular}

${ }^{\text {a }}$ Mean of 64 lines in each environment.

${ }^{\mathrm{b}}$ Mean of 64 lines across all the environments.

a

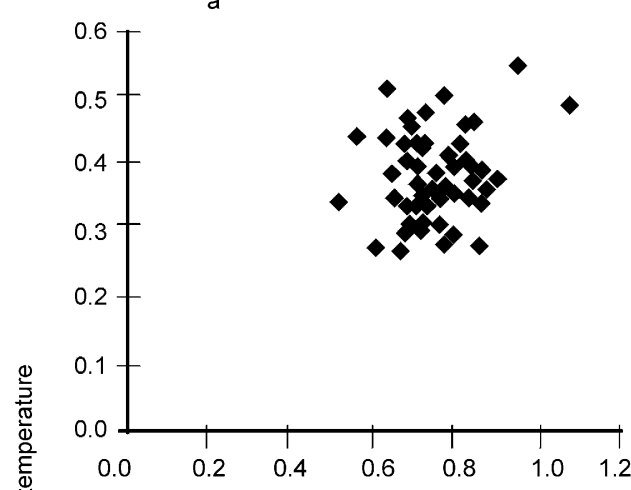

c

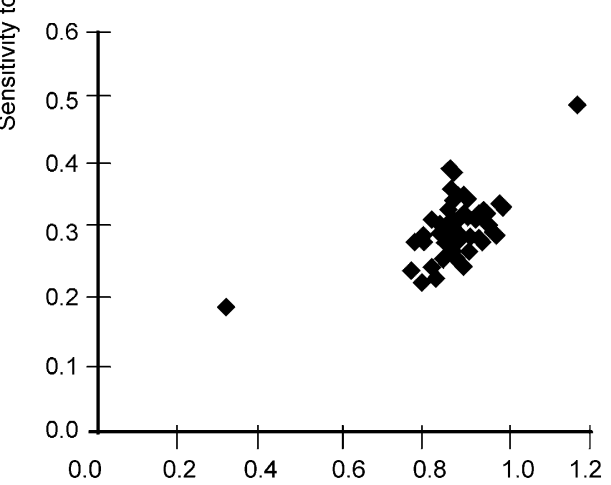

b

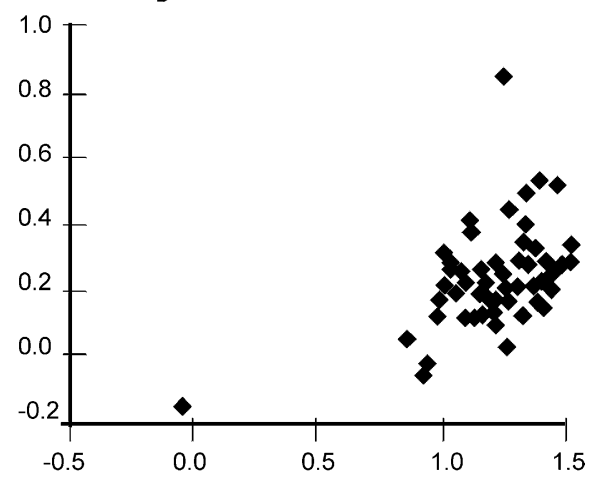

d

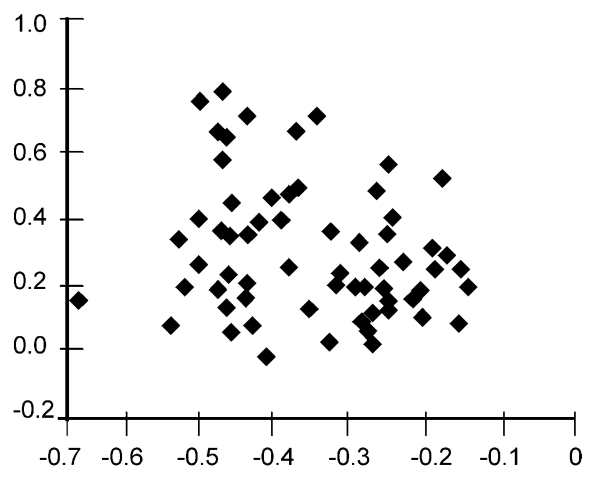

Sensitivity to cool temperature

Fig. 3. Differences in relative sensitivities in responses to cool and warm temperatures for times in days from (a) sowing to $50 \%$ flowering, (b) flowering to maturity, (c) sowing to maturity, and (d) plant height (in $\mathrm{cm}$ ) expressed as the duration under the coolest or warmest temperature relative to the optimal temperature. 


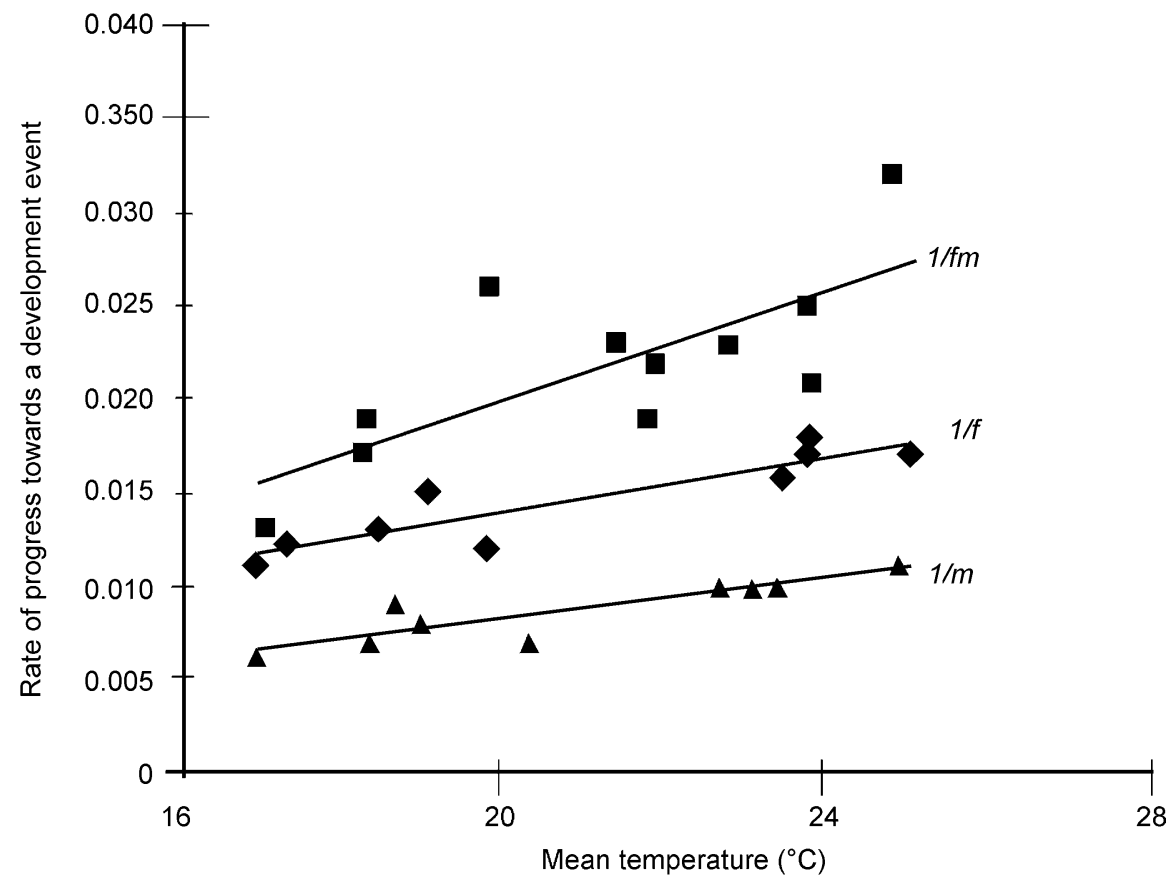

Fig. 4. Relationship between progress from sowing towards flowering (1/f), flowering to maturity (1/fm) and sowing to maturity (1/m) and mean temperatures for pigeonpea line ICPL 84023.

90011 were sensitive to cool temperatures, while ICPL 90054, ICPL 87109, and ICPL 90001 were relatively more sensitive to warm temperatures.

Eq. (1) detected significant differences in $1 / f$ indicating the transgression of $T_{\mathrm{O}}$ in the range of temperatures studied $\left(17.8-26.8^{\circ} \mathrm{C}\right)$. In all the 64 lines, $1 / f$ was much slower than expected at the mean temperatures of $26.8^{\circ} \mathrm{C}$ experienced at Mtwapa (Fig. 4). Mean maximum, minimum, and mean pre-flowering temperatures revealed that mean minimum temperatures were warmer $\left(22.7^{\circ} \mathrm{C}\right)$ at Mtwapa than at other locations. When $1 / f$ was regressed to mean pre-flowering maximum, minimum, and mean temperatures, the resulting $R^{2}$ of $67 \%$ for maximum, $77 \%$ for minimum, and $72 \%$ for mean temperatures indicated that minimum temperatures may have greater influence on $f$ than presently acknowledged. Being the only environment, i.e., only one point, Mtwapa was excluded from further analysis.

Estimates of optimum temperatures $\left(T_{\mathrm{o}}\right)$ at which the rate of development to flowering was fastest varied from 23.8 to $26.1^{\circ} \mathrm{C}$. Base temperature $\left(T_{\mathrm{b}}\right)$ calculated as $-a / b$ from the sub-optimal thermal equation (4) varied from 5.1 to $10.0^{\circ} \mathrm{C}$. A combined regression line was used to describe the entire data set of the 63 Indian lines, which originated from ICRISAT, India. The linear model used for the combined data set for the relationship between $1 / f$ and mean pre-flowering temperatures described by a single equation had the value of $a=-0.0054($ S.E. $=0.00018)$ and $b=0.0009$ $($ S.E. $=0.00030)$ with an $R^{2}$ value of $92 \%$. Further, the analysis gave a common base temperature of $6.0^{\circ} \mathrm{C}$ for the 63 pigeonpea lines.

Unlike for times from sowing to flowering, Eq. (1) did not detect transgression of optimal temperature for the period between flowering and maturity in all the 64 lines (Fig. 4). However, the sensitivity of $1 / \mathrm{fm}$ was strong and positive in the range of temperature sampled $\left(17.8-25.4^{\circ} \mathrm{C}\right)$ indicating that warmer temperatures hastened the advance from flowering to maturity. Estimated optimum temperatures ranged between 24 and $32^{\circ} \mathrm{C}$. With the exception of KAT $60 / 8$, no significant differences were realised in the magnitude of $b$ for the remaining 63 lines. A common estimate of $a=-0.0125$ and $b=0.0016$ described the relations between $1 / f m$ and mean temperatures 
$\left(R^{2}=0.80\right)$ well. By comparing the relative sensitivities to temperature $(b)$ for $1 / f$ and $1 / f m$, i.e., pre- and post-flowering durations, it is clear that the lines were more sensitive to temperature during post-flowering than pre-flowering periods (Fig. 3).

\section{Discussion}

The environments used in the present study exposed the lines to mean temperatures ranging from 17.3 to $26.8^{\circ} \mathrm{C}$ and represent most of the major pigeonpeagrowing areas of eastern and southern Africa, but the photoperiods experienced ranged only from 12.6 to $13.0 \mathrm{~h}$ per day, which are typical of those encountered near the equator.

Across the 11 environments, $f, m$, and $f m$ varied, with cool temperatures lengthening and warm temperatures shortening the durations of these development phases. The delay was more pronounced for $\mathrm{fm}$ in the coolest temperature environment experienced at Kabete. The shortest time to $f, m$, and $f m$ (most inductive environment) occurred at Kiboko where temperatures were warm $\left(23-25^{\circ} \mathrm{C}\right)$ (Table 3$)$. The results of this study are consistent with those of McPherson et al. (1985) and Turnbull and Ellis (1987) who reported that cooler $\left(16^{\circ} \mathrm{C}\right)$ temperatures delayed and warmer $\left(24-28^{\circ} \mathrm{C}\right)$ temperatures hastened times to flowering. In the present study, only one temperature environment, $26.8^{\circ} \mathrm{C}$, was supra-optimal and only for $f$, and not for $f m$ (Table 4). Chauhan et al. (1993) reported that $f$ was relatively early at ICRISAT research station in India $\left(17^{\circ} \mathrm{N}\right.$; mean temperature $\left.27^{\circ} \mathrm{C}\right)$ and delayed at Hisar in India $\left(27^{\circ} \mathrm{N} ; 31.5^{\circ} \mathrm{C}\right)$. Since short-duration pigeonpea is less sensitive to photoperiod, especially in the range $12-15 \mathrm{~h}$ per day (Turnbull et al., 1981; Turnbull and Ellis, 1987; Omanga et al., 1995), the delay at Hisar was most probably because the crop was exposed to supraoptimal temperatures.

With exception of KAT 60/8, there was little variation among lines in $f, m$, and $f m$ in the most inductive environment. The largest variation actually occurred in the least inductive environment $\left(17.3^{\circ} \mathrm{C}\right)$, which implies that for extra-short- and short-duration lines, selection for sensitivity to temperature, particularly low temperature, should be conducted under cooler temperature environments.

Sharma et al. (1981) classified pigeonpea based on $f$ into three main maturity groups: early, medium, and late. They further subdivided each of these groups (Sharma et al., 1981). Early-duration was subdivided into five; group 0 with $f<60$ days, group I with $f=61-70$ days, II with $f=71-80$ days, III with $f=81-90$ days, and IV with $f=91-100$ days; medium-duration into group $\mathrm{V}$ with $f=101-110$ days and group VI with $f=111-130$ days; and late-duration into group VII with $f=131-140$ days, group VIII with $f=141-160$ days, and group IX with $f>160$ days (Table 5 ). ICRISAT presently classifies pigeonpea into four duration groups based on $f$ and $m$, extra-short- $(f<60$ days $)$, short- $(f=61-80$ days $)$, medium- ( $f=81-130$ days $)$ and long-duration $(f>$ 131 days). Under the most conducive environment, the 64 lines used in the study fell into extra-short- and short-duration groups (Table 5), which under Sharma

Table 5

Number of lines falling into ICRISAT classification based on times to flowering at ICRISAT, Patancheru in India $\left(17^{\circ} \mathrm{N} ; 27^{\circ} \mathrm{C}\right)$

\begin{tabular}{llllll}
\hline Classification group & Time to flowering & Duration & & \multicolumn{2}{l}{ Temperature environments } \\
\cline { 3 - 5 } & & & Optimal $\left(23.5^{\circ} \mathrm{C}\right)$ & Warmest $\left(26.8^{\circ} \mathrm{C}\right)$ & Coolest $\left(17.3^{\circ} \mathrm{C}\right)$ \\
\hline 0 & $<60$ & Extra-short & 34 & - & - \\
I & $61-70$ & Short & 29 & - & - \\
II & $71-80$ & Short & 1 & 36 & - \\
III & $81-90$ & Medium & - & 27 & - \\
IV & $91-100$ & Medium & - & - & 37 \\
V & $101-110$ & Medium & - & 1 & 4 \\
VI & $111-130$ & Medium & - & - & 64 \\
Total & & & 64 & 64 & \\
\hline
\end{tabular}

${ }^{a}$ Classification based on Sharma et al. (1981). 
et al.'s (1981) classification would fall into groups 0, I and II. Under the warmest temperatures experienced in the study, the lines maintained their ranking but were delayed in $f$ (Table 5). However, the line rankings in the coolest temperature environment were different from those in the optimal temperature for $f, m$, and $f m$ (Table 5). This indicates that it may not be possible to predict the phenology of short-duration lines under sub-optimal temperatures when selection for earliness is carried out under optimal and supra-optimal temperatures. Therefore, a breeding program that has a mandate to develop lines for a wide range of environments, including areas with low temperatures, should include a test site with low temperatures.

We believe that areas where pigeonpea is grown can be expanded to include temperate environments and cool areas near the tropics. Silim et al. (1995) reported that long-duration pigeonpea lines have a lower optimal temperature $\left(<17^{\circ} \mathrm{C}\right)$ for $f$ than short-duration lines and flower earliest at Kabete where temperatures were coolest. Long-duration lines, however, have a long pre inductive phase (long juvenile phase) and are more sensitive to photoperiod than extra-short- and short-duration lines. We recommend that a program can be initiated where crosses are made between extrashort- and short-duration lines on the one hand, and long-duration lines on the other hand. The segregating population should be tested in a number of environments and one of the sites should have low temperatures. When selecting lines from the segregating population for low optimal temperature for $f, m$, and $f m$, those with long pre-inductive phase should be excluded, and those with relative insensitivity to photoperiod should be maintained. A cool site such as Kabete in Kenya would be an ideal testing environment. Selection for insensitivity to photoperiod can be achieved by extending daylength through artificial lighting.

The fact that delays caused by coolest temperature in relation to the optimal were approximately two fold for $f$, three fold for $m$, and five fold for $f m$ is an indication that these phasic developmental stages are differentially temperature sensitive. Fig. 3 clearly shows that the relative sensitivity to cool temperatures of the short-duration lines is more pronounced for the duration between times to flowering and maturity $(\mathrm{fm})$ and that some lines are relatively less affected by cool temperatures. These lines could be used as short-duration parents for making crosses with longduration lines. Alternatively, KAT 60/8 could be crossed with other short-duration lines to incorporate insensitivity during $f m$.

In this work, the linear model described the rate of development well in the $17.3-26.8^{\circ} \mathrm{C}$ range experienced along the Kenyan transect (Fig. 4), and could be used to determine the response of extra-short- and short-duration pigeonpeas to mean temperature. The model reported by Summerfield et al. (1991), which described plant response to mean temperature and photoperiod in terms of rates of development, allows times to flowering in the photoperiod sensitive lines grown in a constant photoperiod or in photoperiods shorter than the critical daylengths to be predicted under naturally fluctuating temperature conditions. The findings of the present study are in agreement with those of Summerfield et al. (1993) in soybean, Roberts and Summerfield (1987) in common bean, Ellis et al. (1994a), Craufurd et al. (1996) in cowpea, and Ellis et al. (1994b) in mungbean.

At Mtwapa, the supra-optimal mean temperature was not high, yet the delay for $f$ was about 20 days compared to the optimal temperature environment at Kiboko. The cause of transgression of optimal temperature detected appeared to be mainly due to warmer mean minimum temperatures. Results for cowpea (Ellis et al., 1994a) and soybean (Myers et al., 1991), however, indicated that warmer night temperatures hastened and hot days delayed time to flowering. Indeed, in the present study, the night temperatures that delayed time to flowering $\left(22.7^{\circ} \mathrm{C}\right)$ were close to the estimated optimal temperatures $\left(23.8^{\circ} \mathrm{C}\right)$ for most of the lines.

The base temperatures $\left(T_{\mathrm{b}}\right)$ for development calculated from this study ranged from 5.1 to $10.0^{\circ} \mathrm{C}$. Some of the values were within the range $7.0-12.5^{\circ} \mathrm{C}$ reported earlier for short-duration pigeonpea lines by Omanga et al. (1995) and for other grain legumes by Imrie and Lawn (1990), and Ellis et al. (1994a,b).

\section{References}

Byth, D.E., Wallis, E.S., Saxena, K.B., 1981. Adaptation and breeding strategies for pigeonpea. In: Proceedings of the International Workshop on Pigeonpea, December 15-19, 1980, Vol. 1. ICRISAT Center, Patancheru, India, pp. 259-270. 
Chauhan, Y.S., Johansen, C., Laxman Singh, 1993. Adaptation of extra-short duration pigeonpea to rainfed semi-arid environments. Exp. Agric. 29, 233-243.

Craufurd, P.Q., Qi, A., Ellis, R.H., Summerfield, R.J., Roberts, E.H., 1996. Development in cowpea (Vigna unguiculata). II. Effect of temperature and saturation deficit on time to flowering in photoperiod-insensitive genotype. Exp. Agric. 32, 13-28.

Ellis, R.H., Lawn, R.J., Summerfield, R.J., Qi, A., Roberts, E.H., Chay, P.M., Brouwer, J.B., Rose, J.L., Yeates, S.J., 1994a. Towards reliable prediction of time to flowering in six annual crops. III. Cowpea (Vigna unguiculata). Exp. Agric. 30, 17-29.

Ellis, R.H., Lawn, R.J., Summerfield, R.J., Qi, A., Roberts, E.H., Chay, P.M., Brouwer, J.B., Rose, J.L., Yeates, S.J., Sandover, S., 1994b. Towards prediction of times to flowering in six annual crops. IV. Cultivated and wild mungbean. Exp. Agric. $30,31-43$.

Imrie, B.C., Lawn, R.J., 1990. Time to flowering in mungbean (Vigna radiata) genotypes and their hybrids in response to photoperiod and temperature. Exp. Agric. 26, 307-318.

McPherson, H.G., Warrington, I.J., Turnbull, H.L., 1985. The effects of temperature and daylength on the rate of development of pigeonpea. Ann. Bot. 56, 597-611.

Myers, J.D., Lawn, R.J., Byth, D.E., 1991. Adaptation of soybean (Glycine max (L.) Merrill.) to the dry seasons of the tropics. I. Genotypic and environmental effects on phenology. Aust. J. Agric. Res. 42, 497-515.

Nene, Y.L., 1991. Pigeonpea research: future research strategies in Africa. In: Laxman Singh, Silim, S.N., Ariyanayagam, R.P., Reddy, M.V. (Eds.), Proceedings of the First Eastern and Southern Africa Regional Legumes (Pigeonpea) Workshop. ICRISAT, Nairobi, Kenya, pp. 1-4.

Nene, Y.L., Sheila, V.K., 1990. Pigeonpea: geography and importance. In: Nene, Y.L., Hall, S.D., Sheila, V.K. (Eds.), The Pigeonpea. CAB International, Wallingford, UK/ICRISAT, Patancheru, India, pp. 1-14.

Omanga, P.A., Summerfield, R.J., Qi, A., 1995. Flowering of pigeonpea (Cajanus cajan) in Kenya: responses of earlymaturing genotypes to location and date of sowing. Field Crops Res. 41, 25-34.

Omanga, P.A., Summerfield, R.J., Qi, A., 1996. Flowering in pigeonpea (Cajanus cajan) in Kenya: responses of mediumand late-maturing genotypes to location and date of sowing. Exp. Agric. 32, 111-128.
Richards, R.A., 1989. Breeding for drought resistance physiological approaches. In: Baker, F.W.G. (Ed.), Drought Resistance in Cereals. CAB International, Wallingford, UK, pp. 65-79.

Roberts, E.H., Summerfield, R.J., 1987. Measurement and prediction of flowering in annual crops. In: Artheton, J.G. (Ed.), Manipulation of Flowering. Butterworths, London, pp. 17-50.

Sharma, D., Reddy, L.J., Green, J.M., Jain, K.C., 1981. International adaptation of pigeonpeas. In: Proceedings of the International Workshop on Pigeonpea, Vol. 1, December 15 19, 1980. ICRISAT Center, Patancheru, India, pp. 71-81.

Silim, S.N., Omanga, P.A., Johansen, C., Laxman Singh, Kimani, P.M., 1995. Use of the Kenya transect for selecting and targeting adapted genotypes to appropriate production systems. In: Silim, S.N., King, S.B., Tuwafe, S. (Eds.), Improvement of Pigeonpea in Eastern and Southern Africa - Annual Research Planning Meeting 1994. ICRISAT, Patancheru, India, pp. 44-54.

Singh, L., Gupta, S.C., Faris, D.G., 1990. Breeding. In: Nene, Y.L., Hall, S.D., Sheila, V.K. (Eds.), The Pigeonpea. CAB International, Wallingford, UK/ICRISAT, Patancheru, India, pp. 375400.

Summerfield, R.J., Lawn, R.J., Roberts, E.H., Ellis, R.H., 1991. Towards the reliable prediction of time to flowering in six annual crops. 1. The development of simple models for fluctuating field environments. Exp. Agric. 27, 11-31.

Summerfield, R.J., Lawn, R.J., Qi, A., Ellis, R.H., Roberts, E.H., Chay, P.M., Brouwer, J.B., Rose, J.L., Shanmugasundaram, S., Yeates, S.J., Sandover, S., 1993. Towards the reliable prediction of time to flowering in six annual crops. II. Soybean (Glycine max). Exp. Agric. 29, 253-289.

Turnbull, L.V., Ellis, E.H., 1987. Effect of incandescent and fluorescent lighting used in photoperiod extension on the vegetative growth and floral development of four lines of pigeonpea. Field Crops Res. 17, 25-36.

Turnbull, L.V., Whiteman, D.C., Byth, D.E., 1981. The influence of temperature and photoperiod on floral development of early flowering pigeonpea. In: Proceedings of the International Workshop on Pigeonpea, Vol. 1, December 15-19, 1980. ICRISAT Center, Patancheru, India, pp. 217-222.

Whiteman, E.S., Byth, D.E., Wallis, E.S., 1985. Pigeonpea (Cajanus cajan (L.) Millsp.). In: Summerfield, R.J., Ellis, R.H. (Eds.), Grain Legume Crops. Collins Professional and Technical Books, London, UK, pp. 658-698. 